\title{
MODEL DISCREPANCY SEBAGAI EVALUASI PROGRAM PENDIDIKAN
}

\author{
Pinton Setya Mustafa \\ Universitas Islam Negeri Mataram \\ pintonsetyamustafa@uinmataram.ac.id
}

\begin{abstract}
Programs designed to advance education continue to progress and develop dynamically. Improving the program requires an evaluation process. There are various evaluation models used in improving educational programs depending on the aspects needed for improvement or refinement. The purpose of this research is to discuss the basic concepts of the discrepancy model evaluation made by Provus. This research is a library study with data obtained through the study of relevant books and articles and then analyzed using a qualitative approach consisting of: (1) data reduction, (2) data display, and (3) drawing conclusions. Evaluation The discrepancy model is one type of appropriate approach in evaluating an educational and learning program. The procedures used in the discrepancy evaluation are (1) design, (2) installation, (3) process, (4) product, and (5) comparison or the fifth in the form of costs and benefits if needed. The result of the discrepancy model evaluation is knowing the gap between the expected conditions and the reality on the ground, so that it can be a guide for the next step in making decisions.
\end{abstract}

Keywords: Evaluation, Discrepancy Model, Education

\begin{abstract}
Abstrak : Program yang disusun dalam memajukan pendidikan terus mengalami kemajuan dan berkembang secara dinamis. Dalam memperbaiki program diperlukan proses evaluasi. Terdapat beragam model jenis evaluasi yang dipakai dalam memperbaiki program pendidikan tergantung aspek yang diperlukan untuk perbaikan maupun penyempurnaan. Tujuan dari penelitian ini adalah membahas tentang konsep dasar evaluasi model discrepancy yang dibuat oleh Provus. Penelitian ini merupakan studi pustaka dengan data yang diperoleh melalui studi dokumen buku dan artikel yang relevan kemudian dianalisis dengan pendekatan kualitatif yang terdiri dari: (1) reduksi data, (2) penyajian data, dan (3) penarikan kesimpulan. Evaluasi Model discrepancy merupakan salah satu jenis pendekatan yang tepat dalam mengevaluasi sebuah program pendidikan maupun pembelajaran. Prosedur yang digunakan dalam evaluasi discrepancy yaitu: (1) desain, (2) instalasi, (3) proses, (4) produk, dan (5) pembandingan atau yang kelima berupa biaya dan manfaat jika diperlukan. Hasil dari evaluasi model discrepancy adalah mengetahui kesenjangan yang terjadi antara kondisi yang diharapkan dengan kenyataan di lapangan, sehingga dapat menjadi petunjuk langkah selanjutnya dalam mengambil keputusan.
\end{abstract}

Kata kunci: Evaluasi, Model Discrepancy, Pendidikan 


\section{PENDAHULUAN}

Kegiatan evaluasi merupakan bagian yang tidak terpisahkan dalam sebuah program, baik dalam program pendidikan maupun pembelajaran. Dalam UndangUndang Republik Indonesia Nomor 20 Tahun 2003 tentang Sistem Pendidikan Nasional, pada bab XVI pasal 57 sampai dengan 59 tentang evaluasi, intinya menyatakan dalam hal pengendalian mutu pendidikan secara nasional, evaluasi merupakan salah satu bentuk penyelenggara pendidikan yang bertanggung jawab kepada pihak terkait. Selain itu, disebutkan bahwa evaluasi dilakukan secara berkala, menyeluruh, transparan, dan sistematis oleh lembaga independen untuk mengevaluasi pelaksanaan standar nasional pendidikan, serta proses evaluasi dan pemantauan harus berkesinambungan ${ }^{1}$. Selain itu dalam Undang-Undang Republik Indonesia Nomor 14 Tahun 2005 tentang Guru dan Dosen Pasal 20a dan 60a dalam melaksanakan tugas keprofesionalan, guru maupun dosen berkewajiban mengevaluasi hasil pembelajaran. Evaluasi dapat memberikan cara yang lebih luas untuk menginformasikan pendidikan guna membantu meningkatkan dan mengembangkan sistem pendidikan ${ }^{23}$. Dengan demikian dapat dikatakan bahwa evaluasi merupakan bagian yang harus dilakukan oleh seorang pendidik untuk meningkatkan kualitas pendidikan dan pembelajaran.

Adapun tujuan evaluasi adalah untuk mendapatkan informasi yang tepat sasaran dan objektif tentang program yang dijalankan ${ }^{4}$. Senada dengan hal tersebut tujuan umum evaluasi program adalah untuk memberikan atau menguangkapkan data sebagai masukan untuk pengambilan keputusan terkait program ${ }^{5}$. Alternatif kebijakan pengambilan keputusan dari evaluasi program dibagi menjadi empat, yaitu: (1) menghentikan program, (2) merevisi program, (3) melanjutkan program, (4) menyebarluaskan program ${ }^{6}$. Evaluasi merupakan sebuah profesi yang merupakan

\footnotetext{
1 Undang-Undang Republik Indonesia Nomor 20 Tahun 2003 tentang Sistem Pendidikan Nasional

${ }^{2}$ Undang-Undang Republik Indonesia Nomor 14 Tahun 2005 tentang Guru dan Dosen

${ }^{3}$ F.Y. Tayibnapis, Evaluasi Program (Jakarta: P2LPTK, 1989), hal. 1.

4 S. Eko Putro Widoyoko, Evaluasi Program Pembelajaran: Panduan Praktis bagi Pendidik dan Calon Pendidik (Yogyakarta: Pustaka Pelajar, 2013), hal. 6.

${ }^{5}$ D. Sudjana, Evaluasi Program Pendidikan Luar Sekolah (Bandung: PT Remaja Rosdakarya, 2006), hal. 48.

${ }^{6}$ Suharsimi Arikunto dan C.S.A. Jabar, Evaluasi Program Pendidikan: Pedoman Teoretis Praktis bagi Mahasiswa dan Praktisi Pendidikan (Jakarta: Bumi Aksara, 2009), hal. 22.
} 
bagian kelengkapan tertentu bagi profesi lain ${ }^{7,8}$. Secara umum, evaluasi program memeriksa program untuk menentukan nilainya dan mengambil keputusan atau membuat rekomendasi untuk penyempurnaan dan keberhasilannya ${ }^{9}$. Penyebab utama dilaksanakannya kegiatan evaluasi adalah untuk mengetahui efektivitas program, sehingga pada saat melaksanakan kegiatan evaluasi selesai diharapkan dapat menjadi dasar bagi pihak-pihak yang bertanggung jawab untuk mengambil keputusan berdasarkan aspek-aspek yang telah dievaluasi. ${ }^{10}$.

Evaluasi program bermanfaat bagi pengambil keputusan untuk menentukan apakah program akan dihentikan, diperbaiki, dimodifikasi, diperluas atau ditingkatkan ${ }^{11}$. Dapat dikatakan tujuan evaluasi memberikan penentuan langkah yang harus dilakukan dalam kelanjutan dari sebuah program yang telah dilaksanakan, sehingga program dijalankan yang diharapkan dapat menjadi lebih baik. Evaluasi juga digunakan dalam dunia pendidikan, sebab evaluasi secara umum merupakan proses yang menentukan kondisi dimana suatu tujuan harus dicapai ${ }^{12}$. Dengan demikian untuk mengetahui pencapaian seberapa besar tujuan pendidikan nasional dapat terlaksana dengan kondisi pendidikan maupun pembelajaran di lapangan maka perlu dilakukan evaluasi.

Dalam ilmu evaluasi terdapat berbagai model yang dapat digunakan dalam mengevaluasi program. Ragam model evaluasi dapat diklasifikasikan berdasarkan penemuan dan pengebangan dari ahli maupun diberi sebutan berdasarkan dengan sifat pola kerjanya ${ }^{13}$. Model evaluasi merupakan desain evaluasi sesuai dengan misi yang akan dibawakan dan kepentingan yang ingin diraih serta ada yang menyesuaikan

7 W.R. Shadish, T.D. Cook, dan L.C... Leviton, Foundations of Program Evaluation: Theories of Practice (Newbury Park: SAGE Publications, 1991), hal. 25; Pinton Setya Mustafa, M.E. Winarno, dan Supriyadi, "Penilaian Pendidikan Jasmani, Olahraga, dan Kesehatan pada Sekolah Menengah Pertama Negeri Kota Malang”, Jurnal Pendidikan: Teori, Penelitian, dan Pengembangan, vol. 4, no. 10 (2019), hal. 1366.

${ }^{8}$ Shadish, Cook, dan Leviton, Foundations of Program Evaluation: Theories of Practice, hal. 25; Mustafa, Winarno, dan Supriyadi, "Penilaian Pendidikan Jasmani, Olahraga, dan Kesehatan pada Sekolah Menengah Pertama Negeri Kota Malang", hal. 1366.

${ }_{9}^{2}$ D.T. Spaulding, Program Evaluation in Practice: Core Concepts and Examples for Discussion and Analysis (San Francisco: Jossey-Bass, 2008), hal. 5.

10 D.L. Kirkpatrick dan J.D. Kirkpatrick, Evaluating Training Program The Four Levels (San Fransisco: Berret-Kohler Publisher, Inc, 2006), hal. 3.

${ }^{11}$ Sudjana, Evaluasi Program Pendidikan Luar Sekolah, hal. 7.

12 Sukardi, Evaluasi Pendidikan Prinsip \& Operasionalnya (Jakarta: Bumi Aksara, 2011), hal. 14.

13 Arikunto dan Jabar, Evaluasi Program Pendidikan: Pedoman Teoretis Praktis bagi Mahasiswa dan Praktisi Pendidikan, hal. 40. 
dengan paham yang dianutnya ${ }^{14}$. Misalnya dalam penelitian evaluasi di atas menggunakan discrepancy model, yaitu model evaluasi yang bertujuan menentukan ketidaksamaan pada komponen mana pada suatu standar maupun untuk mengetahui apakah ada perbedaan ${ }^{15}$. Jadi dengan kata lain salah satu model evaluasi untuk mengetahui tingkat perbedaan suatu standar dengan kondisi di lapangan adalah model discrepancy atau yang dikenal dengan model kesenjangan ${ }^{16}$. Model evaluasi discrepancy adalah model pemanfaatan yang telah diuji dan umum diterima untuk digunakan dalam mengevaluasi program akademik ${ }^{17}$. Sehingga dapat dikatakan model evaluasi tersebut tepat digunakan dalam bidang pendidikan dan pembelajaran.

Berdasarkan uraian di atas melaksanakan evaluasi program pendidikan maupun pembelajaran memang merupakan tugas pokok seorang evaluator dalam manajemen sekolah atau institusi. Akan tetapi, bukan berarti hanya evaluator saja yang harus memahami model-model evaluasi program pendidikan dan pembelajaran. Calon pendidik, para pendidik, mahasiswa, dan praktisi lain, hendaknya memahami bagian alternatif model evaluasi khususnya evaluasi discrepancy model. Sebab dalam suatu program kegiatan apapun khususnya dalam pendidikan maupun pembelajaran secara tidak langsung perlu diketahui tingkat kesenjangannya, yaitu perbedaan standar dengan kenyataan. Penguasaan evaluasi program juga bisa dilakukan melalui mempelajari teori secara luas dan mendalam, kemudian dilanjutkan melalui kegiatan praktis yang terencana sehingga evaluasi program dikuasai secara sinergis ${ }^{18}$. Manfaat dari penguasaan teoritis dan praktis dalam evaluasi program berfungsi agar program yang dilaksanakan dapat menjadi lebih baik serta lebih berstandar yang diharapkan.

\footnotetext{
${ }^{14}$ Widoyoko, Evaluasi Program Pembelajaran: Panduan Praktis bagi Pendidik dan Calon Pendidik, hal. 172.

15 Supriyono, Evaluasi Program untuk Pendidikan dan Pelatihan (Malang: FIP UM, 2013), hal. 12.

16 J. Mbulu, Evaluasi Program Konsep Dasar, Pendekatan, Model, dan Prosedur (Malang: Proyek OPF IKIP Malang, 1995), hal. 83.

17 Kirk Alter, "Electrical Construction Management Specialization Program: A Formative Evaluation", Journal of Construction Education, vol. 3, no. 2 (1998), hal. 64.

18 Sukardi, Evaluasi Program Pendidikan dan Pelatihan (Jakarta: Bumi Aksara, 2014), hal. 14.
} 


\section{METODE PENELITIAN}

Pendekatan studi pustaka digunakan dalam pengumpulan informasi dalam penelitian ini. Prosedur dalam penelitian studi pustaka ini terdiri dari: (1) pengumpulan data dengan cara melakukan tinjauan dokumen dari kumpulan buku dan artikel yang relevan tentang evaluasi model discrepancy dalam pendidikan, (2) penyajian temuan teori-teori yang relevan, (3) melakukan analisis, serta (4) menarik kesimpulan. Data yang telah diperoleh dalam studi dokumen, kemudian dianalisis menggunakan pendekatan kualitatif dengan cara: (1) reduksi data, (2) penyajian data, dan (3) penarikan kesimpulan.

Referensi primer yang digunakan dalam studi pustaka ini antara lain: (1). Evaluasi Program Pendidikan: Pedoman Teoretis Praktis bagi Mahasiswa dan Praktisi Pendidikan karya Arikunto, S., \& Jabar, C. S. A Tahun 2009; (2) Evaluasi Program Pembelajaran: Panduan Praktis bagi Pendidik dan Calon Pendidik karya Widoyoko, S. E. P Tahun 2013; (3) Evaluasi Program Konsep Dasar, Pendekatan, Model, dan Prosedur karya Mbulu, J. Tahun 1995; (4) Program Evaluation: Alternative Approaches and Practical Guidelines karya Fitzpatrick, J. L., Sanders, J. R., \& Worthen, B. R. Tahun 2011; dan (5) Electrical Construction Management Specialization Program: A Formative Evaluation pada Journal of Construction Education, Volume 3 Nomor 2 karya Alter, K. Tahun 1998.

\section{HASIL DAN PEMBAHASAN}

\section{Evaluasi}

Sebelum mengkaji tentang konsep evaluasi model discrepancy maka perlu memahami tentang konsep evaluasi terlebih dahulu, berikut ini merupakan pengertian evaluasi secara umum. Evaluasi sebagai proses penggambaran, perolehan, dan pemberian informasi yang berguna untuk menentukan pemilihan alternatif keputusan $^{19,20}$. Evaluasi adalah kegiatan mengumpulkan informasi tentang bagaimana

19 Robert P. Grobe, "Evaluation-What's It All About?”, NASSP Bulletin, vol. 62, no. 422 (1978), hal. 6; Ina Magdalena, Alvi Ridwanita, dan Bunga Aulia, "Evaluasi Belajar Peserta Didik", Pandawa : Jurnal Pendidikan dan Dakwah, vol. 2, no. 1 (2020), hal. 126. 
sesuatu bekerja, yang kemudian digunakan untuk mengidentifikasi alternatif yang tepat saat menentukan keputusan ${ }^{21}$. Evaluasi dapat dianggap sebagai cara untuk menentukan altertatif keputusan yang tepat tentang nilai dan efektivitas program promosi kesehatan, membandingkan berbagai jenis program, menghilangkan komponen program yang lemah, memenuhi persyaratan sumber pendanaan, atau memberikan informasi tentang program. Proses evaluasi berlangsung sebelum, selama, dan setelah pelaksanaan program ${ }^{22}$. Evaluasi dapat dipahami sebagai penyedia informasi dilakukan secara sistematis untuk pembuat keputusan ${ }^{23}$. Evaluasi sebagai koleksi sistematis dan analisis bukti mengenai hasil program untuk membuat keputusan tentang relevansi, kinerja, dan cara alternatif untuk menyampaikannya atau untuk mencapai hasil ${ }^{24}$. Evaluasi adalah proses pengumpulan, penggambaran, interpretasi, dan penyajian informasi yang berkesinambungan dan sistematis tentang suatu program sehingga dapat digunakan sebagai dasar pengambilan keputusan, perumusan kebijakan, dan pengembangan program selanjutnya. ${ }^{25}$. Selain itu evaluasi dapat diartikan suatu proses pemberian pertimbangan mengenai nilai dan arti sesuatu yang dipertimbangkan. Sesuatu tersebut dapat berupa orang, benda, kegiatan, keadaan, atau suatu kesatuan/ kelompok tertentu seperti materi pelajaran, kurikulum, proyek dan program ${ }^{26}$.

Dari pengertian evaluasi yang telah diuraikan maka dapat disimpulkan bahwa evaluasi ialah proses yang sistematis dalam mengumpulkan informasi dari suatu kegiatan dan selanjutnya data dari informasi tersebut dijadikan alternatif pengambilan keputusan agar kegiatan tersebut dapat mencapai hasil yang diinginkan.

20 Grobe, "Evaluation-What's It All About?", hal. 6; Magdalena, Ridwanita, dan Aulia, "Evaluasi Belajar Peserta Didik", hal. 126.

21 Arikunto dan Jabar, Evaluasi Program Pendidikan: Pedoman Teoretis Praktis bagi Mahasiswa dan Praktisi Pendidikan, hal. 2.

22 James F. McKenzie, Brad L. Neiger, dan Rosemary Thackeray, Planning, Implementing and Evaluating Health Promotion Programs: A Primer, 6 edisi (San Francisco: Pearson, 2013), hal. 384.

23 Supriyono, Evaluasi Program untuk Pendidikan dan Pelatihan, hal. 11.

${ }^{24}$ Cheryl Poth et al., "Towards a Definition of Evaluation within the Canadian Context: Who Knew This Would Be So Difficult?", Canadian Journal of Program Evaluation / La Revue canadienne d'évaluation de programme, vol. 29, no. 1 (2014), hal. 95.

${ }^{25}$ Widoyoko, Evaluasi Program Pembelajaran: Panduan Praktis bagi Pendidik dan Calon Pendidik, hal. 6.

26 Roswati, "Evaluasi Program/Proyek (Pengertian, Fungsi, Jenis, dan Format Usulan)", Jurnal Pendidikan Penabur, vol. 7, no. 11 (2008), hal. 65. 
Hasil dari evaluasi dapat dibedakan menjadi dua yaitu hasil secara kuantitatif dan kualitatif ${ }^{27}$. Hasil kuantitatif biasanya berupa nilai antara 0-100, 0-10, atau dapat dikatakan dengan rentangan nilai yang telah ditentukan kemudian diberi kategori, misalnya sangat baik, baik, cukup baik, atau kurang. Sedangkan hasil kualitatif berupa anjuran, arahan, rekomendasi, atau formulasi, misalnya agar kegiatan tersebut dapat berjalan dengan baik maka perlu direvisi pada bagian tertentu.

Dalam Undang-Undang Republik Indonesia Nomor 20 Tahun 2003 tentang Sistem Pendidikan Nasional Pasa1 ayat 21 menyatakan evaluasi pendidikan adalah kegiatan pengendalian, penjaminan, dan penetapan mutu pendidikan terhadap berbagai komponen pendidikan pada setiap jalur, jenjang, dan jenis pendidikan sebagai bentuk pertanggungjawaban penyelenggaraan pendidikan. Jadi dalam dunia pendidikan evaluasi merupakan tanggung jawab penyelenggara pendidikan yang diperlukan untuk pengendalian, penjaminan, penetapan mutu dari komponen pendidikan $^{28}$.

\section{Evaluasi Program}

Apabila evaluasi dikaitkan dengan suatu program maka pengertiannya adalah sebagai berikut. Evaluasi program merupakan upaya untuk menentukan secara akurat tingkat implementasi kebijakan dengan mengetahui efektivitas masing-masing komponen ${ }^{29}$. Evaluasi program adalah penerapan metode sistematis untuk menjawab pertanyaan tentang operasi dan hasil program termasuk pemantauan berkelanjutan atas program serta studi satu kali proses program atau dampak program melalui pendekatan yang digunakan didasarkan pada metodologi penelitian ilmu sosial dan standar profesional ${ }^{30}$. Evaluasi program adalah penilaian terhadap suatu kegiatan yang dilakukan untuk memperoleh hasil atau outcomes yang berlangsung dalam jangka waktu yang tidak terbatas ${ }^{31}$. Evaluasi program diartikan sebagai proses mencari informasi, menemukan informasi dan menentukan informasi yang diuraikan secara

\footnotetext{
${ }^{27}$ Sukardi, Evaluasi Program Pendidikan dan Pelatihan, hal. 15.

28 Undang-Undang Republik Indonesia Nomor 20 Tahun 2003 tentang Sistem Pendidikan Nasional

${ }^{29}$ Arikunto dan Jabar, Evaluasi Program Pendidikan: Pedoman Teoretis Praktis bagi Mahasiswa dan Praktisi Pendidikan, hal. 18.

${ }^{30}$ Kathryn E. Newcomer, Harry P. Hatry, dan Joseph S. Wholey, Handbook of Practical Program Evaluation, 4 edisi (United States: John Wiley \& Sons, Inc, 2015), hal. 8.

${ }^{31}$ Roswati, "Evaluasi Program/Proyek (Pengertian, Fungsi, Jenis, dan Format Usulan)", hal. 66.
} 
sistematis tentang perencanaan, nilai, tujuan, manfaat, efektifitas dan kegunaan sesuatu dengan kriteria dan tujuan yang telah ditentukan ${ }^{32}$. Evaluasi program didefinisikan sebagai kegiatan sistematis untuk mengumpulkan, mengolah, menganalisis, dan menyajikan data sebagai masukan untuk pengambilan keputusan ${ }^{33}$. Evaluasi program berfungsi memberikan informasi untuk pengontrol agar diketahui kelemahan atau menyimpangan program sehingga membantu dalam menentukan tindak lanjut ${ }^{34}$.

Dari beberapa uraian para ahli tersebut, maka dapat disimpulkan bahwa evaluasi program adalah kegiatan yang sistematis dalam mengumpulkan data untuk mendapatkan informasi dari suatu program yang berguna untuk mengetahui ketercapaian tujuan dari keterlaksanaannya program tersebut, yang langkah selanjutnya berguna dalam pengambilan keputusan.

\section{Evaluasi Model Discrepancy}

Kata discrepancy berarti kesenjangan, discrepancy evaluation model dikembangkan oleh Malcolm Provus (1971) merupakan model yang menonjolkan gap implementasi program, sehingga evaluasi yang dilakukan oleh evaluator terhadap program dapat mengukur besarnya gap yang ada pada masing-masing komponen ${ }^{35}$. Evaluasi model discrepancy sebagai proses untuk menyetujui standar program, menentukan apakah terdapat perbedaan antara beberapa aspek program dan standarnya, dan menggunakan informasi kesenjangan untuk mengidentifikasi kelemahan program ${ }^{36}$.

Evaluasi kesenjangan (discrepancy evaluation) berfungsi untuk mengetahui tingkat kesesuaian antara standard (kriteria) yang sudah ditetapkan dengan penampilan aktual program yang bersangkutan. Selanjutnya evaluasi kesenjangan adalah suatu metode untuk mengidentifikasikan; perbedaan atau kesenjangan antara

32 Ashiong P. Munthe, "Pentingnya Evaluasi Program di Institusi Pendidikan: Sebuah Pengantar, Pengertian, Tujuan dan Manfaat", Scholaria: Jurnal Pendidikan dan Kebudayaan, vol. 5, no. 2 (2015), hal. 13.

${ }^{33}$ Sudjana, Evaluasi Program Pendidikan Luar Sekolah, hal. 21.

${ }^{34}$ Mbulu, Evaluasi Program Konsep Dasar, Pendekatan, Model, dan Prosedur, hal. 15.

35 Arikunto dan Jabar, Evaluasi Program Pendidikan: Pedoman Teoretis Praktis bagi Mahasiswa dan Praktisi Pendidikan, hal. 48.

36 Alter, "Electrical Construction Management Specialization Program: A Formative Evaluation", hal. 64. 
tujuan khusus yang ditetapkan dengan penampilan aktual ${ }^{37}$. Selain itu, evaluasi model kesenjangan (discrepancy model) adalah untuk mengetahui tingkat keselarasan antara baku (standar atau kriteria yang ditetapkan) yang sudah ditetapkan dalam program dengan kinerja (performance / hasil pelaksanaan program) semestinya dari program tersebut $^{38}$. Karakteristik evaluasi model discrepancy yaitu proses untuk (1) menyetujui standar (yang digunakan untuk tujuan), (2) menentukan apakah ada perbedaan antara kinerja dari beberapa aspek program dan standar yang ditetapkan untuk kinerja, dan (3) menggunakan informasi tentang perbedaan untuk memutuskan apakah akan memperbaiki, mempertahankan, atau menghentikan program atau beberapa aspeknya $^{39}$. Tujuan evaluasi kesenjangan adalah untuk menentukan apakah akan memperbaiki, mempertahankan, atau menghentikan sebuah program ${ }^{40}$.

Jadi dengan demikian dapat disimpulkan bahwa evaluasi model discrepancy adalah evaluasi yang bertujuan untuk mengetahui tingkat kesenjangan dari standar yang ditetapkan dengan penerapan pelaksanaan program tersebut. Selanjutnya informasi dari yang didapatkan digunakan untuk pengambilan keputusan yang meliputi: mempertahankan, memperbaiki, atau menghentikan program tersebut.

Adapun kesenjangan dapat terjadi antara dua atau lebih elemen (variabel) ${ }^{41}$, berikut ini adalah penjabarannya:

(1) Kesenjangan antara perencanaan dan implementasi program atau material program yang aktual (actual program operations).

(2) Kesenjangan antara predicted (diprediksi) and obtained (diperoleh) program outcomes.

(3) Kesenjangan antara posisi siswa dengan standar kompetensi yang ingin dicapai

(4) Kesenjangan antara tujuan yang ditetapkan dengan hasil yang dicapai

(5) Kesenjangan apa yang dihipotesiskan dengan perubahan program (pendidikan dan atau pelatihan).

${ }^{37}$ Mbulu, Evaluasi Program Konsep Dasar, Pendekatan, Model, dan Prosedur, hal. 83.

38 Agustanico Dwi Muryadi, "Model Evaluasi Program dalam Penelitian Evaluasi”, Jurnal Ilmiah PENJAS, vol. 3, no. 1 (2017), hal. 4; Pinton Setya Mustafa dan M.E. Winarno, "Penerapan Pendekatan Saintifik dalam Aktivitas Belajar Pendidikan Jasmani, Olahraga, dan Kesehatan di SMK Negeri 4 Malang", Jurnal Penjakora, vol. 7, no. 2 (2020), hal. 81.

39 Jody L. Fitzpatrick, James R. Sanders, dan Blaine R. Worthen, Program Evaluation: Alternative Approaches and Practical Guidelines (Boston: Pearson, 2011), hal. 156.

40 Alter, "Electrical Construction Management Specialization Program: A Formative Evaluation", hal. 64.

${ }^{41}$ Mbulu, Evaluasi Program Konsep Dasar, Pendekatan, Model, dan Prosedur, hal. 85. 
(6) Kesenjangan antar sistem.

Adapun kesenjangan yang dapat dievaluasi dalam program pendidikan meliputi: (1) kesenjangan antara rencana dengan implementasi program, (2) kesenjangan antara yang diduga atau doprediksi akan didapat dengan yang sesungguhnya direalisasikan, (3) kesenjangan antara status kemampuan dengan standar kemampuan yang ditetapkan, (4) kesenjangan tujuan, (5) kesenjangan tentang komponen program yang dapat diganti, dan (6) kesenjangan dalam sistem yang tidak konsisten $^{42}$.

Jadi dari uraian di atas maka dapat disimpulkan bahwa kesenjangan yang dapat dievaluasi dalam model discrepancy meliputi: (1) kesenjangan perencanaan dengan pelaksanaan program, (2) kesenjangan prediksi dan perolehan yang didapat dalam program, (3) kesenjangan antara kemampuan dengan kemampuan yang standar, (4) kesenjangan tujuan dan hasil yang dicapai, (5) kesenjangan hipotesis dengan perubahan program, dan (6) kesenjangan sistem yang berubah-ubah.

Provus seorang yang mencetuskan evaluasi model discrepancy menentukan ketika sebuah program dikembangkan terdapat empat tahap perkembangan, kemudian dia menambahkan sebuah tahap kelima yang bersifat opsional, lima tahap tersebut meliputi: (1) definisi, (2) instalasi, (3) proses (produk sementara), (4) produk, (5) analisa biaya dan manfaat (opsional) ${ }^{43}$. Menurut Qomari (2008:179) Model evaluasi kesenjangan mencakup empat dimensi, yaitu design, operation program, interim products, dan terminal products. Sedangkan menurut ${ }^{44}$. Model evaluasi kesenjangan mengajukan lima langkah proses evaluasi termasuk: (1) klarifikasi dari rancangan program, (2) menilai pelaksanaan program, (3) menilai hasilnya dalam jangka pendek, (4) menilai hasil jangka panjangnya, dan (5) menilai biaya dan manfaat. Selanjutnya Mbulu (1995) menjabarkan langkah-langkah model evaluasi kesenjangan meliputi: (1) tahap penyusunan desain, (2) tahap pemasangan instalasi (installation), (3) tahap proses (pengumpulan data), (4) tahap pengukuran tujuan (product), dan (5) tahap

${ }^{42}$ Muryadi, "Model Evaluasi Program dalam Penelitian Evaluasi”, hal. 4.

43 Fitzpatrick, Sanders, dan Worthen, Program Evaluation: Alternative Approaches and Practical Guidelines, hal. 156.

${ }^{44}$ David Nevo, "The Conceptualization of Educational Evaluation: An Analytical Review of the Literature", Review of Educational Research, vol. 53, no. 1 (1983), hal. 122. 
pembandingan (program comparison) ${ }^{45}$. Adapun pendapat Muryadi (2017) Model evaluasi discrepancy memiliki lima tahap yaitu desain, instalasi, proses, produk, dan membandingkan ${ }^{46}$.

Jadi dari pernyataan di atas maka dapat disimpulkan bahwa langkah-langkah evaluasi model discrepancy meliputi: (1) definisi atau desain, (2) instalasi atau pemasangan, (3) proses, (4) produk, dan (5) pembandingan atau yang kelima berupa biaya dan manfaat jika diperlukan.

\section{Prosedur Pelaksanaan Evaluasi Model Discrepancy}

Adapun langkah-langkah dalam pelaksanaan model evaluasi kesenjangan meliputi: (1) tahap penyusunan desain, (2) tahap pemasangan instalasi (installation), (3) tahap proses (pengumpulan data), (4) tahap pengukuran tujuan (product), dan (5) tahap pembandingan (program comparison) ${ }^{47}$. Tahapan dalam evaluasi model discrepancy meliputi: (1) definisi program, (2) instalasi program, (3) proses program, (4) produk program, dan (5) membandingkan standar dengan kinerja program aktual ${ }^{48}$. Adapun penjelasan dari masing-masing tahap tersebut adalah sebagai berikut.

(1) Tahap penyusunan desain atau definisi program adalah menilai perancangan program dengan menentukan terlebih dahulu input, proses, dan output yang diperlukan, dan kemudian dengan mengevaluasi kelengkapan dan konsistensi internal rancangan. Kegiatan yang dilakukan antara lain:

(a) Merumuskan tujuan program

(b) Menyiapkan audiens, personil, dan kelengkapan lain

(c) Menentukan kriteria (standard) dalam bentuk rumusan yang menunjuk pada sesuatu yang dapat di ukur

(2) Tahap pemasangan instalasi (installation) adalah untuk menilai tingkat pemasangan program terhadap standar program tahap 1 apakah sesuai dengan rancangan atau didefinisikan. Kegiatan yang dilakukan antara lain:

${ }^{45}$ Mbulu, Evaluasi Program Konsep Dasar, Pendekatan, Model, dan Prosedur, hal. 84.

${ }^{46}$ Muryadi, "Model Evaluasi Program dalam Penelitian Evaluasi”, hal. 4.

${ }^{47}$ Mbulu, Evaluasi Program Konsep Dasar, Pendekatan, Model, dan Prosedur, hal. 84.

48 Alter, "Electrical Construction Management Specialization Program: A Formative Evaluation", hal. 64-5. 
(a) Menilai kembali penetapan kriteria (standard) yang telah ditetapkan pada tahap penyusunan desain

(b) Meninjau/memonitor program yang sedang dilaksanakan

(c) Meneliti kesenjangan antara apa yang telah direncanakan dengan apa yang telah dicapai

(3) Tahap proses (pengumpulan data) adalah menilai hubungan antara variabel yang akan diubah dan proses yang digunakan untuk mempengaruhi perubahan. Kegiatan yang dilakukan antara lain: mengadakan evaluasi terhadap tujuan-tujuan manakah yang telah dan akan dicapai.

(4) Tahap pengukuran tujuan (product) adalah menilai apakah rancangan program mencapai tujuan utamanya yaitu mengadakan analisis data dan menetapkan tingkat output yang diperoleh.

(5) Tahap pembandingan (program comparison), yaitu membandingkan hasil yang telah dicapai dengan tujuan yang telah ditetapkan sebelumnya. Pada masing-masing dari empat tahap standar yang ditetapkan dibandingkan dengan kinerja program aktual untuk menentukan apakah ada perbedaan. Dalam tahap ini evaluator menulis semua penemuan tentang kesenjangan. Selanjutnya, disajikan kepada pengambil kebijakan/pembuat keputusan, agar mereka dapat memutuskan kelanjutan dari program tersebut. Kemungkinan hasil keputusan yang ditetapkan adalah (a) menghentikan program, (b) mengganti atau merevisi program, (c) meneruskan program yang telah didesain atau, (d) memodifikasi dan menyempurnakan tujuannya.

\section{Ketepatan Evaluasi Model Discrepancy}

Model evaluasi kesenjangan dapat diterapkan untuk mengevaluasi program pemrosesan yaitu program yang kegiatan pokoknya mengubah bahan mentah (input) menjadi bahan jadi sebagai hasil atau keluaran (output $)^{49}$. Misalnya program pemrosesan yaitu pembelajaran dan program kepramukaan. Selain itu, model kesenjangan tepat dan sesuai sekali digunakan untuk mengevaluasi program layanan yaitu sebuah serangkaian kegiatan yang bertujuan untuk memenuhi kebutuhan pihak

49 Arikunto dan Jabar, Evaluasi Program Pendidikan: Pedoman Teoretis Praktis bagi Mahasiswa dan Praktisi Pendidikan, hal. 55. 
tertentu sehingga merasa puas sesuai dengan tujuan program. Misalnya program layanan yaitu program perpustakaan dan program koperasi. Selanjutnya model evaluasi kesenjangan cocok dan dapat digunakan untuk mengevaluasi semua program umum yaitu program yang tidak memiliki ciri utama. Misalnya program makanan tambahan anak sekolah (PMTAS) dan Program peringatan lustrum sekolah (PPLS).

Jadi dengan demikian dapat disimpulkan bahwa evaluasi kesenjangan tepat digunakan dalam program pemrosesan, program pelayanan, dan program umum.

Model discrepancy paling efektif dalam situasi berikut ${ }^{50}$ :

(1) Ketika jenis evaluasi yang diinginkan bersifat formal, dan programnya dalam tahap formatif, bukan sumatif.

(2) Ketika evaluasi didefinisikan sebagai manajemen informasi yang berkesinambungan yang menangani perbaikan dan penilaian program, dan dimana evaluasi merupakan komponen pengembangan program.

(3) Dimana tujuan evaluasi adalah memperbaiki, mempertahankan atau menghentikan suatu program.

(4) Dimana penekanan utama evaluasi adalah definisi program dan penginstalan program.

(5) Dimana peran evaluator adalah fasilitator, pemeriksa standar, pengamat perilaku aktual, dan ahli desain.

(6) Ketika pada setiap tahap kinerja program evaluasi dibandingkan dengan tujuan program (standar) untuk mengetahui perbedaan.

(7) Dimana prosedur evaluasi program dirancang untuk mengidentifikasi kelemahan dan membuat keputusan mengenai koreksi atau penghentian.

(8) Dimana konstruk teoritis adalah bahwa semua tahapan program terus memberikan umpan balik satu sama lain.

(9) Jika kriteria untuk menilai program mencakup evaluasi dengan cermat apakah:

(a) Program ini memenuhi kriteria program yang telah ditetapkan

(b) Tindakan yang sebenarnya diambil dapat diidentifikasi, dan

(c) Suatu tindakan dapat diambil untuk menyelesaikan semua perbedaan

50 Alter, "Electrical Construction Management Specialization Program: A Formative Evaluation", hal. 65. 


\section{Keuntungan dan Keterbatasan Evaluasi Model Discrepancy}

Setiap model evaluasi tentunya memiliki keuntungan dan keterbatasan berikut ini akan disajikan keuntungan dan keterbatasan dari evaluasi model discrepancy ${ }^{51}$. Evaluasi model discrepancy memiliki keuntungan menggunakan konsep langsung yang mendasar untuk evaluasi. Berikut ini adalah penjabarannya.

(1) Dengan jelas mengidentifikasi apa yang akan dievaluasi dengan berkonsentrasi pada penentuan tujuan,

(2) Keseimbangan evaluasi kemudian difokuskan pada perbandingan hasil aktual dengan tujuan yang dinyatakan,

(3) Konsep yang sangat bersih yang mudah diikuti dan harus menghasilkan hasil yang pasti,

(4) Gambaran ini menyederhanakan model sebenarnya, namun menangkap esensi dari keuntungan utama model ini.

Evaluasi model discrepany memiliki keterbatasan karena fokusnya terlalu sempit dengan pendekatan yang berorientasi pada tujuan. Berikut ini adalah keterbatasan dari evaluasi model discrepancy.

(1) Tidak memiliki komponen evaluatif yang nyata (memfasilitasi pengukuran dan penilaian tujuan daripada menghasilkan penilaian eksplisit atas jasa atau nilai),

(2) Tidak memiliki standar untuk menilai pentingnya perbedaan yang diamati antara sasaran dan tingkat kinerja,

(3) Mengabaikan nilai dari tujuan itu sendiri,

(4) Mengabaikan alternatif penting yang harus diperhatikan dalam merencanakan program pendidikan,

(5) Mengabaikan transaksi yang terjadi dalam program atau kegiatan yang sedang dievaluasi,

(6) Mengabaikan konteks dalam evaluasi yang berlangsung,

(7) Mengabaikan hasil penting selain yang tercakup dalam tujuan (hasil kegiatan yang tidak diinginkan),

(8) Menghilangkan bukti nilai program yang tidak tercermin dalam tujuannya sendiri,

51 Gordon William Barrett, "Educational Evaluation: Two Theoretical Models in a CorporateBased Application" (The University of British Columbia, 1998), hal. 27-8. 
(9) Mempromosikan pendekatan evaluasi yang linier dan tidak fleksibel.

Evaluasi model discrepany dipertimbangkan dari perspektif aplikasinya, mungkin memiliki keuntungan praktis apabila digunakan di lingkungan dimana fokus pada umumnya mencapai pencapaian yang obyektif.

\section{KESIMPULAN}

Adapun inti sari tujuan dari evaluasi yaitu alternatif pengambilan keputusan agar kegiatan yang telah dilaksanakan dapat mencapai hasil yang diinginkan. Dalam evaluasi model discrepancy yaitu bertujuan untuk mengetahui tingkat kesenjangan dari standar yang ditetapkan dengan penerapan pelaksanaan program kegiatan. Selanjutnya informasi kesenjangan dari yang didapatkan, digunakan untuk pengambilan keputusan dalam program kegiatan yang dengan alternatif: (1) mempertahankan, (2) memperbaiki, atau (3) menghentikan program tersebut. Adapun langkah-langkah evaluasi model discrepancy antara lain: (1) definisi atau desain, (2) instalasi atau pemasangan, (3) proses, (4) produk, dan (5) pembandingan atau yang kelima berupa biaya dan manfaat jika diperlukan. Evaluasi kesenjangan tepat digunakan dalam program pemrosesan, program pelayanan, dan program umum. Evaluasi model discrepancy memiliki keuntungan menggunakan konsep langsung yang mendasar untuk evaluasi, sedangkan keterbatasan evaluasi model discrepancy memiliki fokus terlalu sempit dengan pendekatan yang berorientasi pada tujuan.

Adapun saran yang direkomendasikan yaitu apabila berkeinginan melakukan penelitian evaluasi hendaknya menentukan model evaluasi terlebih dahulu. Evaluasi model discrepancy yang dikembangkan oleh Provus merupakan evaluasi yang bertujuan untuk mengetahui tingkat kesenjangan yang terjadi antara standar yang ditetapkan dengan kinerja yang dilakukan. Evaluasi model ini salah satu model evaluasi yang tepat digunakan dalam program pendidikan dan pembelajaran yang bertujuan untuk mencari kesenjangan antara standar dan pelaksanaan di lapangan dalam pengambilan keputusan. Dengan adanya keuntungan dan keterbatasan dari evaluasi model discrepancy maka sebaiknya digunakan dalam konteks yang umumnya mencapai tujuan secara objektif. 


\section{DAFTAR PUSAKA}

Alter, Kirk, "Electrical Construction Management Specialization Program: A Formative Evaluation", Journal of Construction Education, vol. 3, no. 2, 1998, hal. $60-72$.

Arikunto, Suharsimi dan C.S.A. Jabar, Evaluasi Program Pendidikan: Pedoman Teoretis Praktis bagi Mahasiswa dan Praktisi Pendidikan, Jakarta: Bumi Aksara, 2009.

Barrett, Gordon William, "Educational Evaluation: Two Theoretical Models in a Corporate-Based Application”, The University of British Columbia, 1998.

Fitzpatrick, Jody L., James R. Sanders, dan Blaine R. Worthen, Program Evaluation: Alternative Approaches and Practical Guidelines, Boston: Pearson, 2011.

Grobe, Robert P., “Evaluation-What's It All About?”, NASSP Bulletin, vol. 62, no. 422, 1978, hal. 1-14 [https://doi.org/10.1177/019263657806242201].

Kirkpatrick, D.L. dan J.D. Kirkpatrick, Evaluating Training Program The Four Levels, San Fransisco: Berret-Kohler Publisher, Inc, 2006.

Magdalena, Ina, Alvi Ridwanita, dan Bunga Aulia, "Evaluasi Belajar Peserta Didik", Pandawa: Jurnal Pendidikan dan Dakwah, vol. 2, no. 1, 2020, hal. 117-27 [https://doi.org/10.24252/idaarah.v1i2.4269].

Mbulu, J., Evaluasi Program Konsep Dasar, Pendekatan, Model, dan Prosedur, Malang: Proyek OPF IKIP Malang, 1995.

McKenzie, James F., Brad L. Neiger, dan Rosemary Thackeray, Planning, Implementing and Evaluating Health Promotion Programs: A Primer, 6 edisi, San Francisco: Pearson, 2013.

Munthe, Ashiong P., "Pentingnya Evaluasi Program di Institusi Pendidikan: Sebuah Pengantar, Pengertian, Tujuan dan Manfaat", Scholaria: Jurnal Pendidikan dan Kebudayaan, vol. 5, no. 2, 2015, hal. 1 [https://doi.org/10.24246/j.scholaria.2015.v5.i2.p1-14].

Muryadi, Agustanico Dwi, "Model Evaluasi Program dalam Penelitian Evaluasi", Jurnal Ilmiah PENJAS, vol. 3, no. 1, 2017, hal. 1-15.

Mustafa, Pinton Setya dan M.E. Winarno, "Penerapan Pendekatan Saintifik dalam Aktivitas Belajar Pendidikan Jasmani, Olahraga, dan Kesehatan di SMK Negeri 4 Malang", Jurnal Penjakora, vol. 7, no. 2, 2020, hal. 78-92.

Mustafa, Pinton Setya, M.E. Winarno, dan Supriyadi, "Penilaian Pendidikan Jasmani, Olahraga, dan Kesehatan pada Sekolah Menengah Pertama Negeri Kota Malang", Jurnal Pendidikan: Teori, Penelitian, dan Pengembangan, vol. 4, no. 10, 2019, hal. 1364-79 [https://doi.org/http://dx.doi.org/10.17977/jptpp.v4i10.12845].

Nevo, David, "The Conceptualization of Educational Evaluation: An Analytical Review of the Literature", Review of Educational Research, vol. 53, no. 1, 1983, hal. 117-28 [https://doi.org/10.3102/00346543053001117].

Newcomer, Kathryn E., Harry P. Hatry, dan Joseph S. Wholey, Handbook of Practical Program Evaluation, 4 edisi, United States: John Wiley \& Sons, Inc, 2015. 
Poth, Cheryl et al., "Towards a Definition of Evaluation within the Canadian Context: Who Knew This Would Be So Difficult?", Canadian Journal of Program Evaluation / La Revue canadienne d'évaluation de programme, vol. 29, no. 1, 2014, hal. 87-103 [https://doi.org/10.3138/cjpe.29.1.87].

Roswati, "Evaluasi Program/Proyek (Pengertian, Fungsi, Jenis, dan Format Usulan)", Jurnal Pendidikan Penabur, vol. 7, no. 11, 2008, hal. 64-71.

Shadish, W.R., T.D. Cook, dan L.C... Leviton, Foundations of Program Evaluation: Theories of Practice, Newbury Park: SAGE Publications, 1991.

Spaulding, D.T., Program Evaluation in Practice: Core Concepts and Examples for Discussion and Analysis, San Francisco: Jossey-Bass, 2008.

Sudjana, D., Evaluasi Program Pendidikan Luar Sekolah, Bandung: PT Remaja Rosdakarya, 2006.

Sukardi, Evaluasi Pendidikan Prinsip \& Operasionalnya, Jakarta: Bumi Aksara, 2011.

Sukardi, Evaluasi Program Pendidikan dan Pelatihan, Jakarta: Bumi Aksara, 2014.

Supriyono, Evaluasi Program untuk Pendidikan dan Pelatihan, Malang: FIP UM, 2013.

Tayibnapis, F.Y., Evaluasi Program, Jakarta: P2LPTK, 1989.

Undang-Undang Republik Indonesia Nomor 14 Tabun 2005 tentang Guru dan Dosen.

Undang-Undang Republik Indonesia Nomor 20 Tabun 2003 tentang Sistem Pendidikan Nasional.

Widoyoko, S. Eko Putro, Evaluasi Program Pembelajaran: Panduan Praktis bagi Pendidik dan Calon Pendidik, Yogyakarta: Pustaka Pelajar, 2013. 